\title{
Cyclic variations of gonad development of an air-breathing fish, Channa striata in the lentic and lotic environments
}

\author{
Nasim Al Mahmud ${ }^{1 \dagger}$, Hassan Md. Hafizur Rahman ${ }^{1 \dagger}$, Golam Mohammod Mostakim', Mohd. Golam Quader Khan?', \\ Md. Shahjahan ${ }^{2}$, Nahid Sultana Lucky ${ }^{1}$ and M. Sadiqul Islam ${ }^{1 *}$
}

\begin{abstract}
The study was conducted to know the cyclic changes in gonadal maturation and to investigate the developmental stages of oocytes and testicular germ cells of an air-breathing fish, Channa striata. Fish were sampled monthly from lentic and lotic environments of three geographical locations of Bangladesh from December to November and the histological analysis of their gonad was done to evaluate the objectives. The highest mean GSI was $5.95 \pm 0.20$ for female in July and $0.14 \pm 0.01$ for male also in July showing that the gonadal development reached its peak during this month. The highest mean oocyte diameter was $1257.50 \pm 24.17 \mu \mathrm{m}$ observed in July implying that the oocyte reached maturity in this month. Histological study of ovary revealed the evidence of early yolk granule stage and late yolk granule stage from April to July. In case of male four stages of spermatogenesis were distinguished and spermatozoa were highly abundant in June and July. So the monthly pooled values of GSI and the analysis of gonadal histology indicated that the peak breeding season of C. striata occurred in July in the lentic and lotic environments. Samples collected from lentic and lotic habitats are suggestive of no difference in the development of the gonad. The results of the present study will be useful for selective breeding programme, conservation and sustainable fishery management of C. striata in its natural habitat.
\end{abstract}

Keywords: Gonadal development, Gonad morphology, Maturation stages, Snakehead murrel, Reproduction

\section{Background}

An air-breathing fish, Channa striata (Bloch 1793), known as snakehead murrel is of economic importance as food fish and has great potential for aquaculture in Bangladesh. The species is known to occur in lakes, rivers and shallow water areas such as rice fields, irrigation canals, ponds, ditches and borrows pits due to its ability to breathe atmospheric air (Jayaram 1999). This fish is well known for its taste, high nutritive value, recuperative and medicinal qualities. Snakehead flesh contains high levels of arachidonic acid which is a precursor for prostaglandin and thromboxin, chemicals that affect

\footnotetext{
* Correspondence: sadiqul1973@yahoo.com

Nasim Al Mahmud and Hassan Md. Hafizur Rahman are considered first authors.

${ }^{\dagger}$ Equal contributors

'Department of Fisheries Biology and Genetics, Faculty of Fisheries, Bangladesh Agricultural University, Mymensingh 2202, Bangladesh Full list of author information is available at the end of the article
}

blood clotting and the fusion of endothelial tissue during wound healing (Mat Jais 1992). The natural population of this species decreases rapidly due to habitat degradation and this species is acknowledged as an endangered fish in Bangladesh (IUCN 1998). But no significant progress has been made so far to bring this species under culture in Bangladesh or restocking in their natural habitat in view to conservation. Studies of the gonad developmental cycle and histological examination of gonads are appropriate to determine the precise spawning period and frequency in a breeding season (Conover 1992). The knowledge about different stages of fish gonadal maturation provides important information necessary to prohibit fishing during the reproduction period; allowing the fishery stock to recover (Noble and Jones 1993).

Hence, efforts should be made to replenish the wild stocks and improve the aquaculture industry of economically important fish species like $C$. striata. Thus the 
research work was aimed to study the gonad developmental cycle of an air-breathing fish, C. striata.

\section{Methods}

A total of 120 C. striata of lentic and lotic sources were collected from three different geographical locations of Bangladesh for one year between the period of December 2012 and November 2013 and all samples were pooled together (Table 1). Animals were maintained and used in accordance with the guidelines of the Bangladesh Agricultural University. Specimens were measured to the nearest $\mathrm{mm}$ (total length-TL and standard length-SL) using digital calipers (Mitutoyo, CD-6CS. Error $=0.01 \mathrm{~mm}$ ), and weighed to the nearest gram by using a digital balance (Toledo, AB-204. Error $=0.01 \mathrm{~g}$ ). The gonads were removed by abdominal dissection and weighed to the nearest gram. The gonadosomatic index (GSI) was obtained according to the equation: GSI $=\mathrm{GW} /$ (TW-GW) $x$ 100, where: GW = gonad weight, and TW = total body weight (Gunn et al. 1989). Then the gonad samples were preserved in $10 \%$ buffered formalin and kept at room temperature.

Representative gonads were randomly taken from each stage of gonadal development to measure diameter of oocytes. At least 50 oocyte samples from anterior, middle and posterior of the ovary were measured by using an ocular micrometer. The oocyte size was calculated by using the formula: length axis plus wide axis divided by two (De Vlaming et al. 1982).

Monthly preserved gonad samples were taken out from the fixative. Then the samples of the central portion of the gonads of $0.5 \mathrm{~cm}$ thickness were put into the cassettes separately for histological examination. They were dehydrated in graded alcohol series, embedded in paraffin, sectioned for 5-7 $\mu \mathrm{m}$ in thickness using a microtome (MICROM HM355S, Germany) and stained with Haematoxylin and Eosin, then mounted in DPX mountant and photographed with an OLYMPUS-CX41 microscope which was equipped with the SONY DSCW220 camera (Gunn et al. 1989). At least two glass slides were prepared for each ovary or testis. Gonad development stages were estimated observing sections under the microscope as immature, maturing, mature and spent phases (Navarao et al. 1989; Morton 1990).

The data were subjected to an analysis of variance (ANOVA), followed by comparison of means using
Duncan's multiple range test to determine significance of each data treatment. All statistical analyses were performed using SPSS v16.

\section{Results \\ Morphology of the ovary}

The ovaries of C. striata were hollow sac-like, paired and more or less elongated structure lying dorsal to the alimentary canal and ventral to the swim bladder. A posterior extension of tunica albuginae united both the ovaries to form an oviduct which opened to the exterior via the oval shaped urogenital papilla. The left ovary was larger than the right in the examined fish. The color of the ovary varied from reddish brown in immature ovaries to light yellowish in mature ovaries.

\section{Morphology of the testis}

The testes of C. striata were white, elongated, paired and ribbed structures. The left lobe of testis was found to be slightly larger than the right one. Two parts of the testis joined posteriorly before entering the cloaca and where they formed the third lobe. They were attached to the body wall by mesenteries. The color of the testis ranged from pinkish to whitish depending on the maturity.

\section{Gonadosomatic index (GSI)}

The value of GSI is the indicator of the status of gonadal development and maturity of individuals. Monthly variations in GSI revealed that both sexes followed nearly the same trend. The GSI value of female was mostly higher than male, especially during and by the end of the spawning periods (Figs. 1 and 2). The minimum values of GSI were detected during September (0.02 \pm 0.00 for male and $0.29 \pm 0.07$ for female) representing the quiescent period of this species. The higher values of GSI appeared from March to July for male and April to July for female. The spawning seasons were June and July for both sexes with a peak in July (0.14 \pm 0.01 for male and $5.95 \pm 0.20$ for female). The GSI was significantly different during the sampling months $(P<0.05)$. There was no difference between lentic and lotic samples.

Table 1 Description of aquatic habitats of C. striata sampling

\begin{tabular}{|c|c|c|c|c|}
\hline \multirow[t]{2}{*}{ City } & \multirow[t]{2}{*}{ Geographic location } & \multicolumn{2}{|l|}{ Habitat } & \multirow{2}{*}{$\begin{array}{l}\text { Sample } \\
\text { collection }\end{array}$} \\
\hline & & Lentic & Lotic & \\
\hline Gaibandha & $25.25^{\circ} \mathrm{N} 89.50^{\circ} \mathrm{E}$ & Brahmaputra, Ghagot & Burungi beel, Halla beel & Local market \\
\hline Mymensingh & $24^{\circ} 45^{\prime} 14^{\prime \prime} \mathrm{N} 90^{\circ} 24^{\prime} 11^{\prime \prime} \mathrm{E}$ & Old Brahmaputra & Chara beel, Kailar beel & Local market \\
\hline Sylhet & $24.8917^{\circ} \mathrm{N} 91.8833^{\circ} \mathrm{E}$ & Kushiyara, Manu, Surma & Hail haor, Hakaluki haor, Tanguar haor, and Kawadighi haor & Local market \\
\hline
\end{tabular}




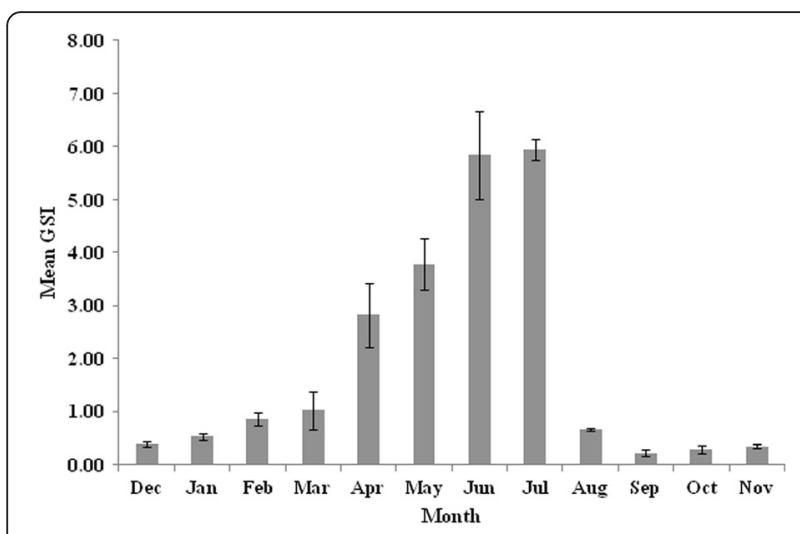

Fig. 1 Monthly variations in the mean GSI of female C. striata

\section{Oocyte diameter}

Oocyte diameter is a measurement to determine the oocyte growth. The mean oocyte diameter of C. striata ranged from $280.00 \pm 12.80 \mu \mathrm{m}$ to $1257.50 \pm 24.17 \mu \mathrm{m}$. The highest oocyte diameter was observed in July (Fig. 3). The oocyte diameter was significantly different $(P<0.05)$ during the sampling months.

\section{Ovarian maturity stages}

Microscopic examination of gonad sections revealed four arbitrary stages of maturity in C. striata: immature, maturing, mature and spent/recovering (Table 2).

\section{Distribution frequency of the ovarian maturity stages}

Figure 4 presents the monthly distribution frequency of maturity stages of $C$. striata ovaries during the study period. Mature ovaries (stage III) were frequent after March and had its most abundance in June and July signaling the period of spawning. Females with empty ovaries (stage IV) were observed only between end of July

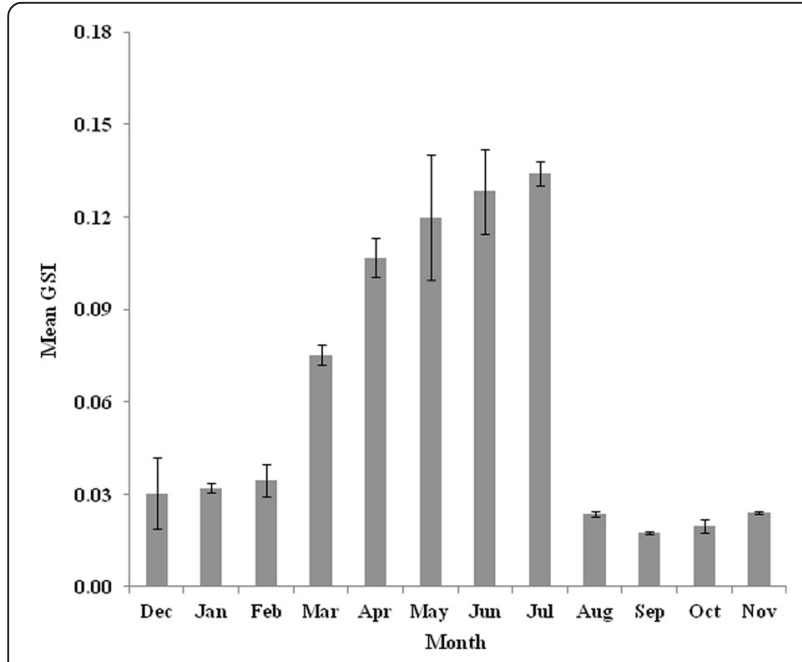

Fig. 2 Monthly variations in the mean GSI of male C. striata

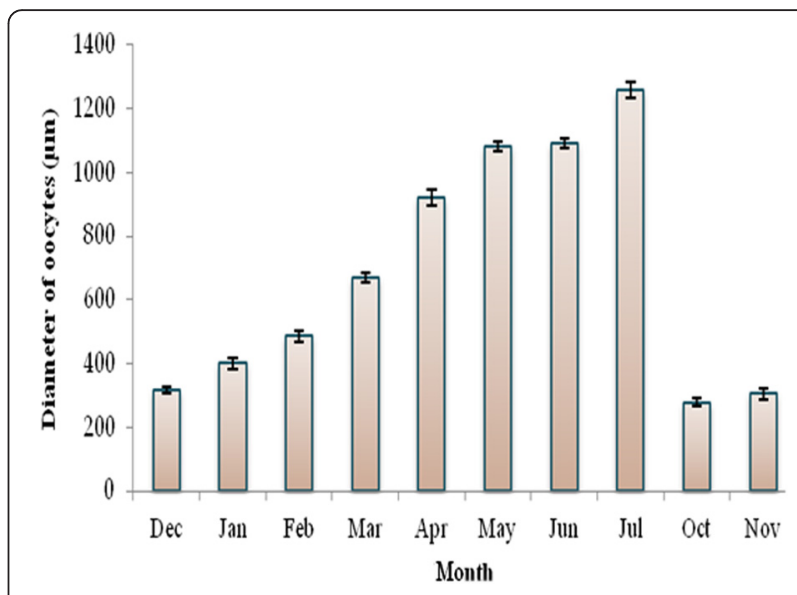

Fig. 3 Monthly variations in oocyte diameter of C. striata; n, total number of oocytes measured

and October. The pooled ovarian maturity patterns were found almost similar both in the lentic and lotic environments.

\section{Stages of oocytes}

Seven of the following stages of oocyte development were identified in C. striata on the basis of histological criteria (Fig. 5).

\section{Chromatin nucleolar stage}

The chromatin nucleolar stage oocytes were small cells with a thin indistinct peripheral zone. They contained a spherical and large nucleus, which occupies the greater part of the cell with one nucleolus. In further development, more than one nucleolus was frequently present.

Table 2 Microscopic description of the maturity stages of the ovaries of C. striata

\begin{tabular}{|c|c|}
\hline Stages & Ovaries \\
\hline Stage I (Immature) & $\begin{array}{l}\text { Oogonia, chromatin nucleolar and early } \\
\text { perinucleolar oocytes were present. } \\
\text { The perinucleolar oocytes had a large } \\
\text { nucleus. }\end{array}$ \\
\hline Stage II (Maturing) & $\begin{array}{l}\text { Partially yolked oocytes and late } \\
\text { perinucleolar oocytes were present. } \\
\text { Partially yolked oocytes contained yolk } \\
\text { vesicles in their cytoplasm. }\end{array}$ \\
\hline Stage III (Mature) & $\begin{array}{l}\text { Advanced yolked oocytes were } \\
\text { abundantly present. The cytoplasms } \\
\text { were filled with yolk granules. These } \\
\text { stages of maturation were observed } \\
\text { from late April to June. }\end{array}$ \\
\hline Stage IV (Spent/Recovering) & $\begin{array}{l}\text { Appearance of empty follicle and few } \\
\text { numbers of oogonia and perinucleolar } \\
\text { oocytes represented the reserved stock } \\
\text { for the further spawning. The spent } \\
\text { gonads appeared in August and September. }\end{array}$ \\
\hline
\end{tabular}


December

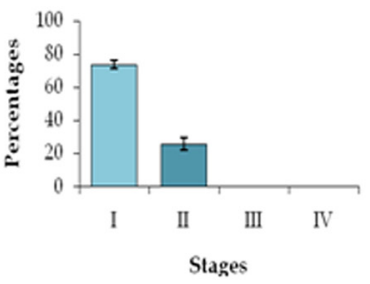

March

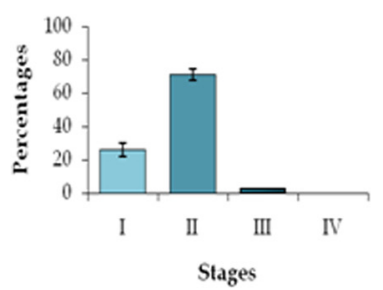

June

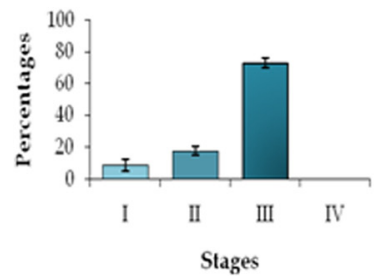

September

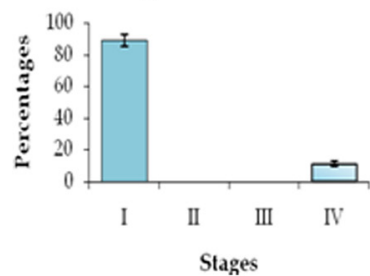

January

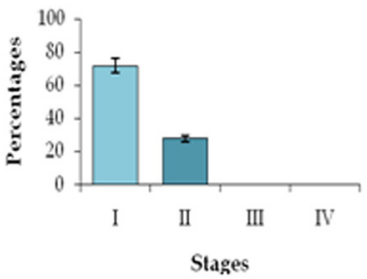

April

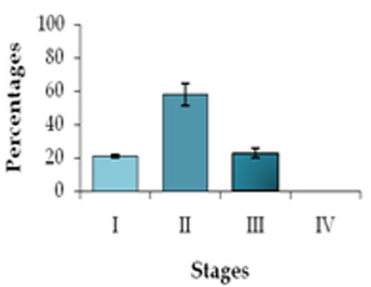

July

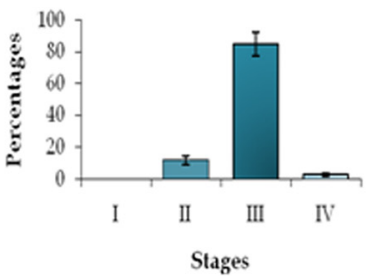

October

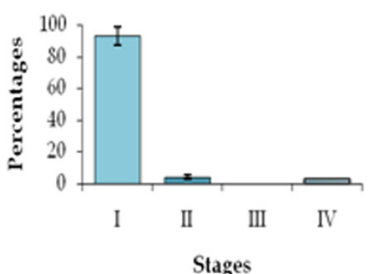

February

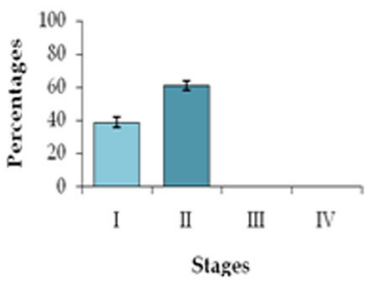

May

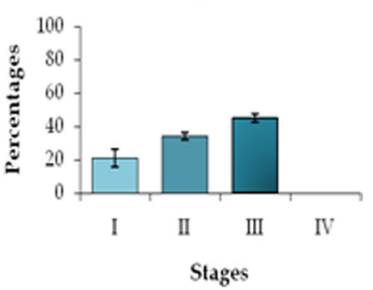

August

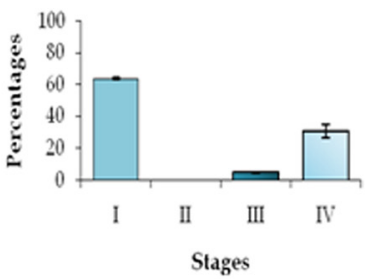

November

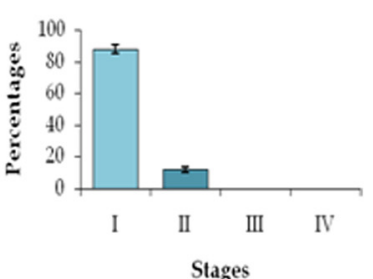

Fig. 4 Monthly frequency distribution of maturity stages of C. Striata ovaries based on microscopic examination. I = Immature stage; II = Maturing stage; III = Mature stage; IV = Spent/Recovering stage

\section{Early perinucleolar stage}

In early perinucleolar stage, oocytes were the most immature type. The oocytes were mostly polygonal and increased in cytoplasmic and nuclear volume together. Nucleoli were smaller, increased in number and appeared around the periphery of the nucleus. Cytoplasm at this stage stained deeply with haematoxylin while nucleus was more or less clear except the nucleoli.

\section{Late perinucleolar stage}

In late perinucleolar stage, oocyte became larger in size. The shape of the oocytes at this stage tended to vary from polygonal to oval with the progress of oocyte development. The nucleus became enlarged and the cytoplasm tended to lose affinity for haematoxylin.

\section{Yolk vesicle stage}

This stage was characterized by the formation of small yolk vesicles in the cytoplasm which appeared as empty unstained vacuoles. These yolk vesicles first appeared at the periphery of the oocyte and gradually spread towards the central nucleus. The nucleoli were usually present at the periphery of the nucleus but in some cases, they also appeared elsewhere in the nucleus.

\section{Early yolk granule stage}

This stage was characterized by the formation of numerous small yolk protein granules in the cytoplasm. These granules stained light pink. They first appeared in the outer cortex and were gradually increased in size and number as they moved towards the inner cortex. Yolk vesicles were eventually no longer apparent in the cytoplasm. 


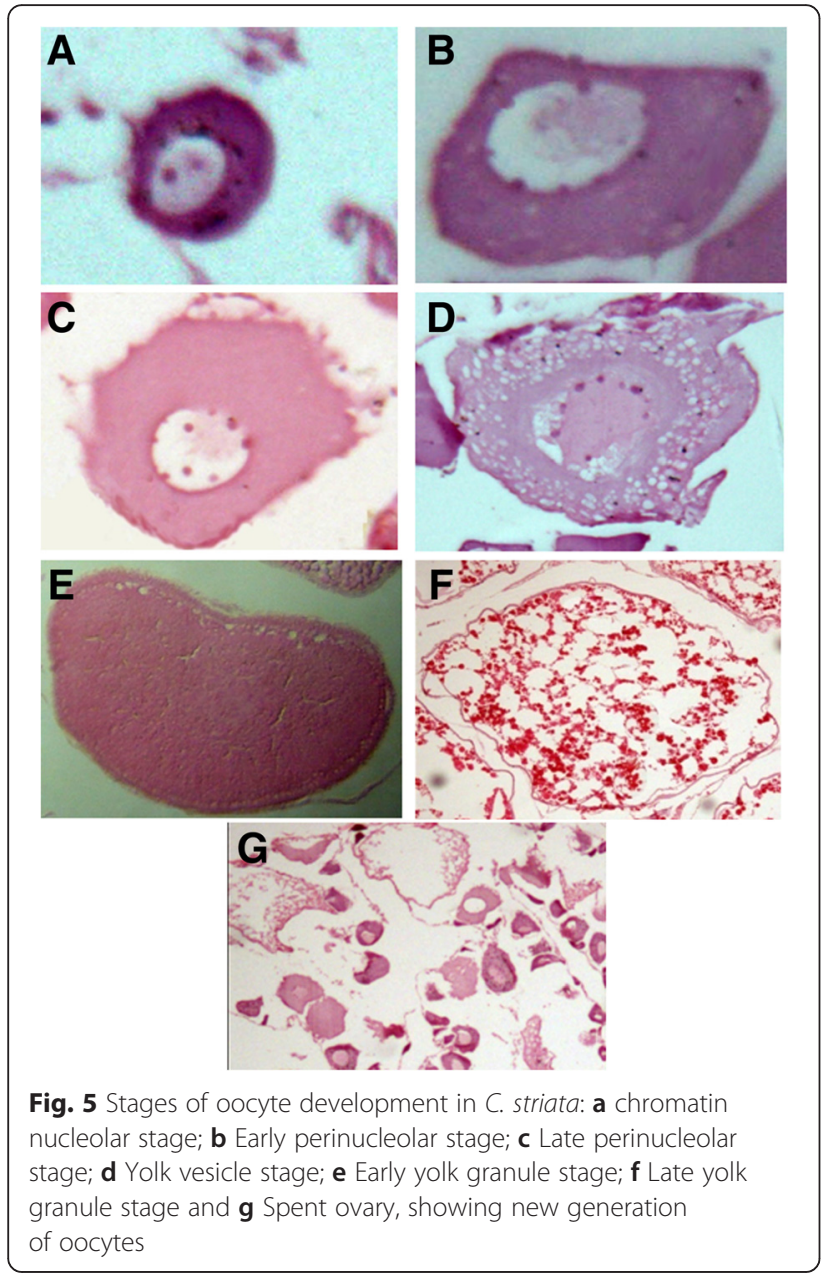

\section{Late yolk granule stage}

The oocytes were greatly increased in diameter at this stage. Fusion of yolk granules and lipid droplets occurred to varying extents appearing deep pink with haematoxylin and eosin.

\section{Spent stage}

In spent stage, ovaries were characterized by the appearance of empty follicle and few numbers of oogonia and perinucleolar oocytes representing the reserved stock for the further spawning.

\section{Maturity stages of testes}

Study of the testes revealed four stages of maturation in C. striata: immature, maturing, mature and spent (Table 3).

\section{Stages of testicular germ cells}

Histological study of the testes revealed four stages of sperm development viz. spermatogonia, spermatocytes, spermatids and spermatozoa (Fig. 6).
Table 3 Microscopic description of maturity stages of the testes of C. striata

\begin{tabular}{ll}
\hline Stages & Testes \\
\hline Stage I (Immature) & Testes were very tiny and translucent \\
& containing many spermatogonia (SG). \\
& A few spermatocytes (SC) were also \\
& thinly scattered (Fig. 6a and b). \\
& Testes at this stage were larger than \\
& the immature stage. Spermatocytes \\
& and spermatids (ST) were more \\
& abundant (Fig. 6c). \\
Stage II (Maturing) & Testes showed the largest volume with \\
& a pinkish white color. A large amount \\
& of spermatozoa (SZ) were observed \\
& (Fig. 6d). Mature testes were mostly \\
& observed in June and July samples. \\
Stage III (Mature) & Testes were darker, opaque and flaccid. \\
& Only residual spermatozoa were found \\
& (Fig. 6e). Spent testes were evident during \\
& August and September.
\end{tabular}

\section{Spermatogonia}

This is the primary stage of spermatogenesis which is the largest germ cell in the testis. It was spherical in shape and the cell membrane was clearly seen. An oval, slightly basophilic nucleus was present in the centre of the cell.

\section{Spermatocytes}

Spermatogonia transformed into spermatocytes by meiotic division which were also spherical in shape containing a nucleus in the centre. These were smaller in size than the spermatogonia.

\section{Spermatids}

Spermatids originated from the spermatocytes but were smaller than the latter. These were spherical shape in which nucleus was not clearly seen for its dark appearance under the microscope.

\section{Spermatozoa}

Spermatozoa, the smallest cells of the spermatogenic lineage appeared as small black colored spots under the microscope. These were the functional male gametes originated from spermatids by the process of spermiogenesis.

\section{Discussion}

The present study documents the changes in the gonadal development of an air-breathing fish, C. striata from lentic and lotic environments. Growth of fish in weight reflects the reproductive cycle, as the gonad mature they increase in weight which adds to the total weight of fish. Samples collected from lentic and lotic habitats are suggestive of no difference in the development of the gonad of $C$. striata. Majority of fish species 


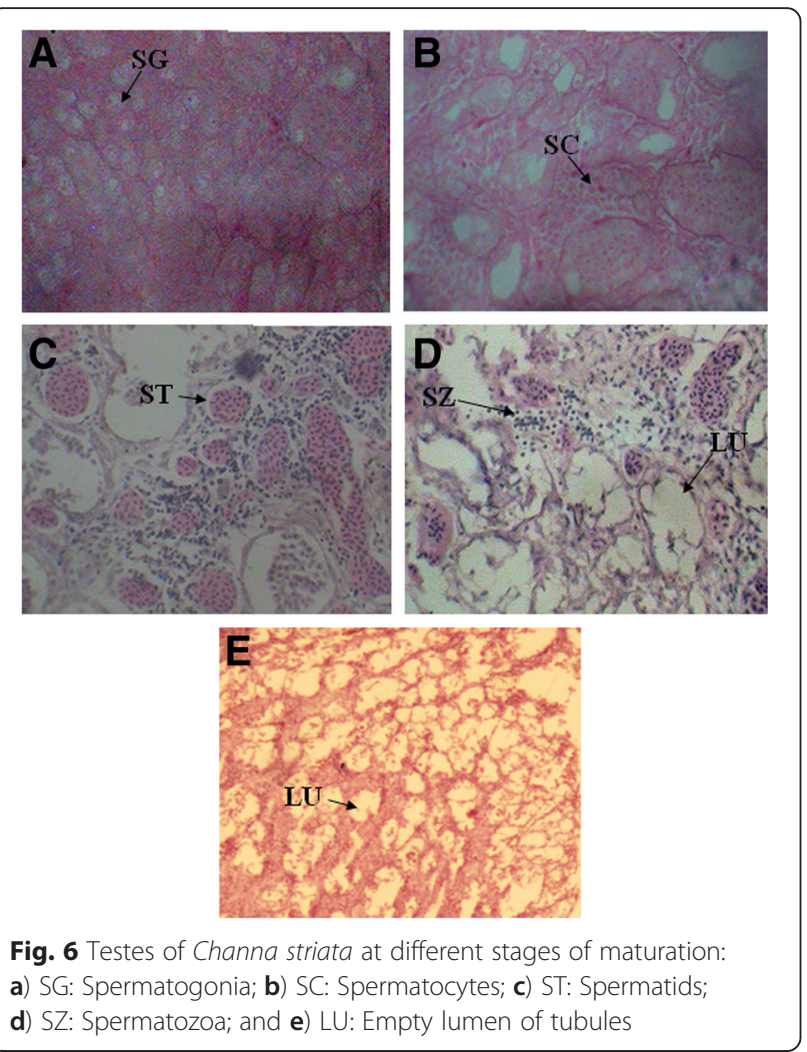

of the temperate region are recorded to breed during the period April to July with the advent of Monsoon. The increasing environmental temperature, fresh rain water with high dissolve oxygen content, longer photoperiod and plenty of natural food during that period act as triggering factors for commencing breeding in majority of fish species in this region (Ali and Kadir 1996; Rinku et al. 2013).

The GSI is one of the main parameters used to evaluate gonadal development in fishes and this method is easier and cheaper to utilize. The high correlation of GSI with number of matured female and male could be utilized to extrapolate peak spawning season. In our study, GSI which indicates growth and maturation of gonad was higher from April to July forming a peak in July for both the male and female. It can be inferred that the fish has only one breeding season largely coincided with the rainy season and spawn during April to July with a peak in July. Like our findings Gaikwad et al. (2009) and Ashwini et al. (2013) also reported that GSI and fecundity of C. gachua was highest during June-July, in $C$. bleheri the highest GSI was recorded by Rinku et al. (2013) during April- July and in C. punctatus, Sunita et al. (2011) and Lalta et al. (2011) reported that it was maximum in the rainy season (May - August). Our results were also very similar with that obtained by Siddiquee (2012) in great snakehead C. marulius from the Sylhet basin and Kirti et al. (2014) in C. marulius from Son river Shadol. The increased water level, inundation of shallow areas, increase in water velocity and turbidity may be responsible for inducing the fish to spawn especially for fishes in the flood plain areas (Winemiller 1987). Thus these add support that the rainy season (June-July in Bangladesh) plays an important role in reproductive period of $C$. striata that collected from lentic and lotic environments.

The highest oocyte diameter was observed in July, implied that the oocyte reached maturity in this month and ovulation is likely to occur. Therefore, the fish would spawn around this month under suitable conditions. Ali and Kadir (1996) and Gaikwad et al. (2009) also noted a highest oocyte diameter in June-July which coincided with the findings of the present study.

Histological observation shows the evidence of gonadal maturation and spawning season. The use of histology in maturity studies has become more and more widespread as it is more consistent and reliable (Tomkeiwicz et al. 2003). The number of gonadal stages and sub-stages can vary according to gonadal development for each species and also according to different criteria used by each author. Four stages of gonadal development were recorded for C. striata in the lentic and lotic environments, through macro- and microscopic analysis. A similar number of stages as described for C. striata, were also observed by Fialho et al. (1998) in Oligosarcus jenynsii.

The process of development of the gonad of C. striata also follows the same basic progression as that described in other teleostean species. Briefly, oogonia and spermatogonia proliferate through mitotic division of primary germ cells, and transform into previtellogenic oocytes and spermatocytes, characteristic of the immature ovary and testis, respectively. The elaboration of yolk in the oocyte marks the beginning of vitellogenesis at the end of which the cell attains its maximum size and undergoes maturation/ovulation, followed by the extrusion of the egg to the exterior.

In this study relatively mature stages of oocytes (early and late yolk granule stage) were evident from April to July. Again abundance of relatively mature stages of testis (spermtids and spermatozoa) was appeared in the testicular sections of June and July samples. Therefore, the evidence of mature stages of gonad and the highest GSI value indicated the peak breeding season of $C$. striata to be in July. The peak breeding season of C. striata from GSI study supports the current finding from histological observation of gonad. The current finding also supports the research in great snakehead $C$. marulius (Siddiquee 2012) who reported that most of the oocytes were in mature stage and the testes were rich in spermatids and spermatozoa in July samples. 


\section{Conclusions}

Overall, the gonad morphology and maturity development class of C. striata in the different geographical locations of Bangladesh did not differ significantly from those of closely related species in lentic and lotic environments. The high values of GSI appeared from March to July for male and April to July for female with the peak in July, indicating the onset of the reproductive season. It is expected that the information generated in the current study will contribute better understanding of gonad developmental cycle of C. striata towards designing conservation plans and captive maturation.

\section{Competing interests}

The authors declare that they have no competing interests.

\section{Authors' contributions}

All authors had full access to all the data in the study and take responsibility for the integrity of the data and the accuracy of the data analysis. All authors read and approved the final manuscript. Study concept and design: MSI. Acquisition of data: NAM, HMHR and GMM. Analysis and interpretation of data: NAM, HMHR and MSI. Drafting of the manuscript: NAM and HMHR. Critical revision of the manuscript for important intellectual content: MSI, MGQK, MS and NSL. Obtained funding: MSI. Administrative, technical, and material support: NAM, HMHR and MSI. Study supervision: MSI.

\section{Acknowledgments}

The authors wish to thank IDRS-BFRI for financial support to MS Islam for making it possible to carry out this research. The assistance of Professor Dr. Harunur Rashid of the Department of Fisheries Management, Bangladesh Agricultural University for the histology work is gratefully acknowledged.

\section{Author details}

${ }^{1}$ Department of Fisheries Biology and Genetics, Faculty of Fisheries, Bangladesh Agricultural University, Mymensingh 2202, Bangladesh. ${ }^{2}$ Department of Fisheries Management, Faculty of Fisheries, Bangladesh Agricultural University, Mymensingh 2202, Bangladesh.

Received: 29 January 2016 Accepted: 16 February 2016

Published online: 11 March 2016

\section{References}

Ali AB, Kadir BKA. The reproductive biology of the cyprinid, Thynnichthys thynnoides (Bleeker), in the Chenderoh Reservoir - a small tropical reservoir in Malaysia. Hydrobiologia. 1996;318:139-51.

Ashwini GG, Girish RG, Raju G, Khillare YK. Study of gonadosomatic index of freshwater fish Channa gachua. Sci Res Rep. 2013;3(1):7-8.

Bloch ME. Naturgeschichte der auslandischen fische, Berlin. Naturg Ausl Fische. $1793 ; 7: 1-144$

Conover DO. Seasonality and the scheduling of life history at different latitudes. J Fish Biol. 1992:41:161-78.

De Vlaming V, Grossman G, Chapman F. On the use of gonosomatic index. Comp Biochem Physiol. 1982;73A:31-9.

Fialho BC, Schifino LC, Verano JR. Biologia reprodutiva de Oligosarcus jenynsii (Gunther) (Characiformes, Characidae) da Lagoa das Custódias, Tramandaí, Rio Grande do Sul, Brasil. Rev Bras Zooltec. 1998;15:775-82.

Gaikwad MV, Shingare SM, Hiwarale DK, More VR, Khillare YK. Study on Ganado-somatic and fecundity relationship in air breathing fish Channa gachua (Ham. 1822) from Godavari near Aurangabad. Afr J Basic Appl Sci. 2009;1:59-61.

Gunn JS, Bruce BD, Furlani DM, Thresher RE, Blaber SJ. Timing and location of spawning of blue grenadier Macruronus novaezelandiae (Teleostii: Merluciidae), in Australian coastal waters. Aust J Marine Fresh Water Res. 1989:40:97-112

IUCN. 1998. List of threatened animals of Bangladesh. Proceedings of the workshop on Bangladesh Red Book of Threatened Animals, February 22, 1998. Dhaka, Bangladesh, pp. 13.
Jayaram KC. The Freshwater fishes of the Indian region. 1st ed. Delhi: Narendra publishing House; 1999. p. 446.

Kirti T, Binay KS, Suman S, Amit T. Study of gonado somatic index of freshwater fish Channa marulius. Int J Sci Res Pub. 2014;4(5):1-2.

Lalta P, Dwivedi AK, Dubey VK, Serajuddin M. Reproductive biology of freshwater murrel, Channa punctatus (Bloch, 1793) from river Varuna (A tributary of Ganga River) in India. J Ecophysiol Occup Health. 2011;11:69-80.

Mat Jais AM. Molecular size of the bio-active component from haruan Channa striatus extract. J Appl Sci. 1992;7:2198-9.

Morton B. The life cycle and sexual strategy of Gafrarium pectinatum (Bivalvia: Veneridae) in Hong Kong Mangrove. Malacol Rev. 1990;23:53-62.

Navarao E, Iglesias JIP, Larranaga A. Interannual variation in the reproductive cycle and biochemical composition of the cockle Cerastoderma edule from Mundace Estuary (Biscay, North Spain). Mar Biol. 1989;101:503-11.

Noble RL, Jones TW. Managing fisheries with regulations. In: Kohler CC, Hubert WA, editors. Inland fisheries management in North America. Bethesda, Maryland, United States of America. 1993. p. 383-402.

Rinku G, Behera S, Bibha CB, Sonmoina B. Sexual dimorphism and gonadal development of a rare murrel species Channa bleheri (Bleher) in Assam. The Bioscan. 2013;8(4):1265-9.

Siddiquee A. Reproductive biology of great snakehead C. marulius from the Sylhet basin, Dissertation, Department of Fisheries Management, Bangladesh Agricultural University, Mymensingh, Bangladesh. 2012.

Sunita K, Kulkarni KM, Gijare SS, Tantarpale VT. Seasonal changes of gonadosomatic index observed in the freshwater fish Channa punctatus. Bios. 2011;6(4):571-3.

Tomkeiwicz J, Tybjerg L, Jespersen A. Micro- and macroscopic characteristic to stage gonadal maturation of female Baltic cod. J Fish Biol. 2003;62:253-75.

Winemiller KO. Feeding and reproductive biology of the currito, Hoplosternum littorale, in the Venezuelan Ilanos with comment on the possible function of the enlarge male pectoral spine. Environ Biol Fish. 1987;20:219-27.
Submit your next manuscript to BioMed Central and we will help you at every step:

- We accept pre-submission inquiries

- Our selector tool helps you to find the most relevant journal

- We provide round the clock customer support

- Convenient online submission

- Thorough peer review

- Inclusion in PubMed and all major indexing services

- Maximum visibility for your research

Submit your manuscript at www.biomedcentral.com/submit
Ciomed Central 